\title{
Kinetic Study of Co-oxidation of Isopropyl Alcohol with EDTA by Pyridinium Fluorochromate
}

\author{
KHUBI LAL REGAR and B. L. HIRAN* \\ Chemical Kinetics and Polymer Research Laboratory, Department of Chemistry, University \\ College of Science, Mohanlal Sukhadia University, Udaipur 313001, Rajasthan, India \\ hiranbl@rediffmail.com
}

Received 29 September 2014 / Accepted 17 October 2014

\begin{abstract}
Kinetic study of co-oxidation of isopropyl alcohol (IPA) with ethylenediaminetetraacetic acid (EDTA) by pyridiniumfluorochromate (PFC) has been investigated in the presence of perchloric acid-water medium at $303{ }^{\circ} \mathrm{K}$. The reaction was carried out in induced pseudo first order conditions. The rate of co-oxidation of IPA and EDTA was ten times greater than the combined rate of addition of both compounds separately. EDTA catalyzed the oxidation of IPA. Free radical test proved two electron transfer oxidation and product was $\mathrm{Cr}(\mathrm{III})$. Thermodynamic parameters and individual order have been determined. Energy of activation of co-oxidation is $42.52 \mathrm{kcal}^{\text {. mol }}{ }^{-1}$, while individually is $67.55 \mathrm{kcal} . \mathrm{mol}^{-1}$ for IPA \& $69.71 \mathrm{kcal} . \mathrm{mol}^{-1}$ for EDTA. Suitable mechanism has been suggested.
\end{abstract}

Keywords: Kinetic study, Co-oxidation, Isopropyl alcohol, IPA, Ethylenediaminetetraaceticacids, EDTA, Pyridinium fluorochromate, PFC

\section{Introduction}

The co-oxidation of organic substrate by PFC under mild acidic condition is an important subject in modern organic synthesis, because many biological reactions are example of co-oxidation and this will help to understand life processes. PFC is an important oxidant due to high solubility of $\mathrm{PFC}$ in organic solvent compared to other $\mathrm{Cr}(\mathrm{VI})$ inorganic compounds, which have low dielectric constant. Some of the important entries in the list of reagents are pyridinium chlorochromate $(\mathrm{PCC})^{1,2}$ pyridinium dichromate $(\mathrm{PDC})^{3}$, pyridinium bromochromate $(\mathrm{PBC})^{4,5}$, quinolinium chlorochromate $(\mathrm{QCC})^{6-9}$, quinolinium fluorochromate $(\mathrm{QFC})^{10-12}$, quinolinium bromochromate $(\mathrm{QBC})^{13-15}$ and quinolinium dichromate $(\mathrm{QDC})^{16,17}$.

Many organic compounds like 2'2 bipyridyl $^{18-21}$ sodium dodecyl sulphate ${ }^{22}$, 1,10 phenathroline ${ }^{23}$ and tartaric $\operatorname{acid}^{24}$ are used as catalyst for many chemical reactions. Ethylendiamminetetraaceticacid (EDTA) is an important organic acid which act as chelating agent, so it is used in removal of toxic metal from over body and also used in determine the hardness of water. It can be also used in agriculture, food processing, cleaners and detergents, pulp and paper manufacturing, textiles manufacturing and dyeing. EDTA catalyzed the oxidation of isopropyl alcohol and also consumed in oxidation reaction, this type of reaction is called co-oxidation reaction. 


\section{Experimental}

Disodium salt of ethylenediaminetetraaceticacid was used after re-crystallization and isopropyl alcohol was used after distillation and purity checked by boiling point. Solvents were purified by the usual procedure and all the chemicals and reagents were of analytical grade. Stock solutions of all reagents were prepared by direct dissolving a known amount in double distilled water. They were stored in refrigerator and were used up to one week.

\section{Preparation of the oxidant (pyridinium fluorochromate)}

PFC was synthesized by standard method as reported in literature ${ }^{25}$ and its purity was checked by an iodometric method, melting point determination and infra red spectral analysis $\left[v_{\max }(\mathrm{KBr})=3033,2366,1616,1466,1299,949\right.$ and $\left.733 \mathrm{~cm}^{-1}\right]$. The melting point of PFC was found to be at $156 \pm 0.1{ }^{\circ} \mathrm{C}$ which was confirmed with the literature value. The stock solution of PFC was prepared in water.

\section{Stoichiometry}

The reaction mixture containing excess of PFC over EDTA and IPA was kept in presence of $\mathrm{HClO}_{4}$ at room temperature for 72 hour. The excess of PFC left in the solution after completion of reaction was determined spectrophotometrically. The concentration of PFC showed that reaction exhibited 3:2 stoichiometry with respect to IPA i.e. Three mole of IPA consumed two moles of PFC and stoichiometry equation for oxidation of EDTA is not predictable because of complex form between EDTA and $\mathrm{PFC}^{26}$.

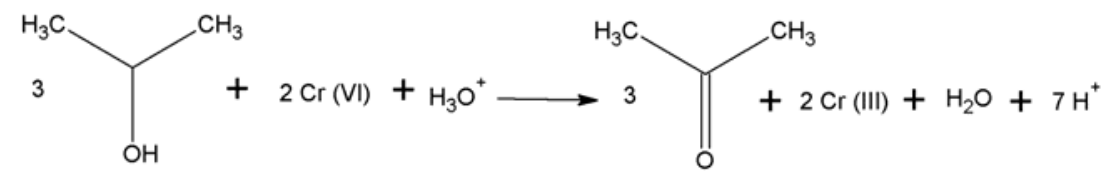

\section{Kinetic measurements}

All experiments were carried out in three parts. In first part we have done the kinetic study of oxidation of IPA with PFC and all parameters were determined. In second part we have done the kinetic study of oxidation of EDTA with PFC and all parameters were determined and in third part we have done the kinetic study of oxidation of mixture i.e. (IPA+EDTA) with PFC. After all the three experiments, we have found that the rate of reaction was increases 10 times from both compounds separately. All reactions were carried out under pseudo-first order condition by keeping excess of IPA and EDTA over PFC, in perchloric acid-water medium. The progress of reaction was followed by estimating the un-reacted $\mathrm{PFC}$ at regular time intervals. The reactions were carried out at constant temperature $( \pm 1 \mathrm{~K})$ and followed by spectrophotometrically. The rate constant was evaluated from the linear plot of log absorbance against time. The activation parameters were calculated from the slope and intercept of linear plot of log k against $1 \backslash \mathrm{T}$ employing Arrhenius's equation.

\section{Product analyses}

The oxidation of IPA and EDTA leads to the formation of acetone and formic acid respectively. The qualitative and quantitative product analysis is carried out under kinetic conditions. Large amount of reaction mixture is taken for the reaction. After the completion of reaction, whole reaction mixture was treated with 2 , 4-dinitrophenylhydrazine ${ }^{27}$. A yellow-orange precipitate obtained which was filtrated, washed, dried and weighted. The weight of product from IPA is $0.20 \mathrm{~g}$ and the weight of product of EDTA is $0.12 \mathrm{~g}$. 
Confirmation of acetone product from IPA and formic acid product from EDTA was done by melting point and infra red analysis.

\section{Results and Discussion}

Oxidation of IPA, EDTA and mixture of both compounds (IPA+EDTA) by PFC has been studied kinetically at fixed temperature. And we found that EDTA catalyzed the oxidation of IPA. This type of catalysis is called organic catalysis. This is proved by various experiments.

\section{Effect of $\left[\mathrm{H}^{+}\right]$}

Table 1 shows the effect of $\mathrm{H}^{+}$ion concentration on reaction rate. Rate of reaction increases with increase in the concentration of perchloric acid $\left[\mathrm{H}^{+}\right] .\left[\mathrm{H}^{+}\right]$was varied from $0.1 \mathrm{M}$ to $2 \mathrm{M}$ in oxidation of IPA, EDTA and IPA + EDTA. The results are summarized in Table 1. Rate of oxidation was found proportional to $\left[\mathrm{H}^{+}\right]$so $\log \mathrm{k} v$ s. $\log \left[\mathrm{H}^{+}\right]$will be straight line and slope will be equal to " $n$ " i.e. order of reaction with respect to $\left[\mathrm{H}^{+}\right]$. Linear relationship was observed (Figure 1, 2,3 ). Hence order with respect to $\left[\mathrm{H}^{+}\right]$in case of only IPA is two (Figure 1), only EDTA is half (Figure 2) and co-oxidation of IPA+EDTA is one (Figure 3). $\Delta \mathrm{k}$ catalysis also calculated.

Table 1. Variation of rate with perchloric acid concentration at typical kinetic condition

\begin{tabular}{ccccc} 
Temp $=30^{\circ} \mathrm{C}$ & substrate $=1 \times 10^{-2} \mathrm{M}$ & $\mathrm{PFC}=1 \times 10^{-3} \mathrm{M}$ & \multicolumn{2}{c}{ solvent $=$ water } \\
\hline $\begin{array}{c}\text { Concentration } \\
\text { of }\left[\mathrm{H}^{+}\right] \text {ion }\end{array}$ & $\begin{array}{c}\mathrm{k} \text { value for } \\
\mathrm{IPA}, \mathrm{k} \times 10^{5}\end{array}$ & $\begin{array}{c}\mathrm{k} \text { value for } \\
\text { EDTA, } \mathrm{k} \times 10^{5}\end{array}$ & $\begin{array}{c}\mathrm{k} \text { value for IPA+ } \\
\text { EDTA, } \mathrm{k} \times 10^{5}\end{array}$ & $\begin{array}{c}\Delta \mathrm{k} \text { catalysis, } \\
\mathrm{k} \times 10^{5}\end{array}$ \\
\hline $0.2 \mathrm{M}$ & 1.63 & 8.70 & 14.04 & 3.71 \\
$0.4 \mathrm{M}$ & 2.41 & 9.02 & 19.99 & 8.56 \\
$0.6 \mathrm{M}$ & 4.79 & 9.10 & 27.80 & 13.91 \\
$0.8 \mathrm{M}$ & 8.55 & 10.70 & 36.70 & 17.42 \\
$1.0 \mathrm{M}$ & 11.24 & 11.05 & 46.40 & 24.11 \\
$1.2 \mathrm{M}$ & 18.53 & 12.09 & 73.60 & 42.98 \\
$1.4 \mathrm{M}$ & 24.49 & 14.60 & 88.42 & 49.33 \\
$1.6 \mathrm{M}$ & 35.42 & 14.90 & 109.04 & 58.72 \\
$1.8 \mathrm{M}$ & 54.61 & 17.30 & 132.70 & 64.36 \\
$2.0 \mathrm{M}$ & 73.54 & 19.10 & 150.70 & 66.01 \\
\hline
\end{tabular}

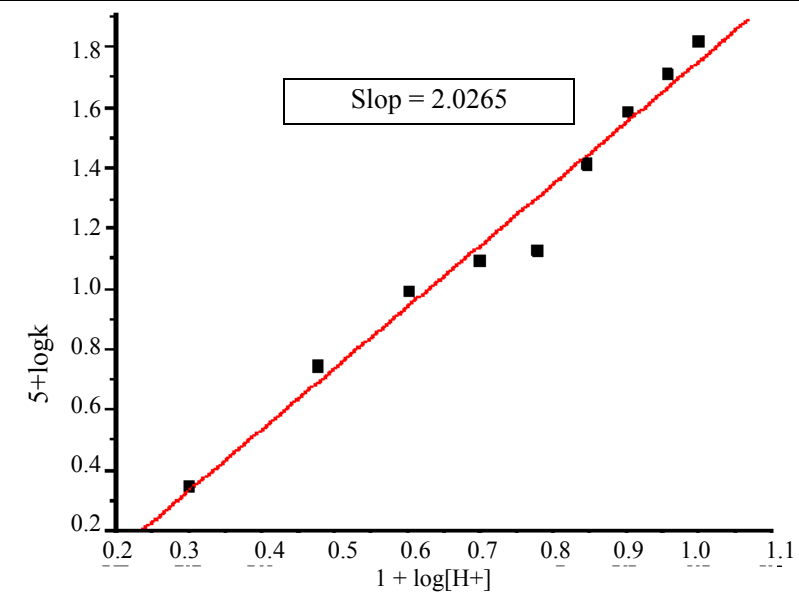

Figure 1. Effect of $\left[\mathrm{H}^{+}\right]$on rate of oxidation of IPA with PFC (log k vs. $\left.\log \left[\mathrm{H}^{+}\right]\right)$ 


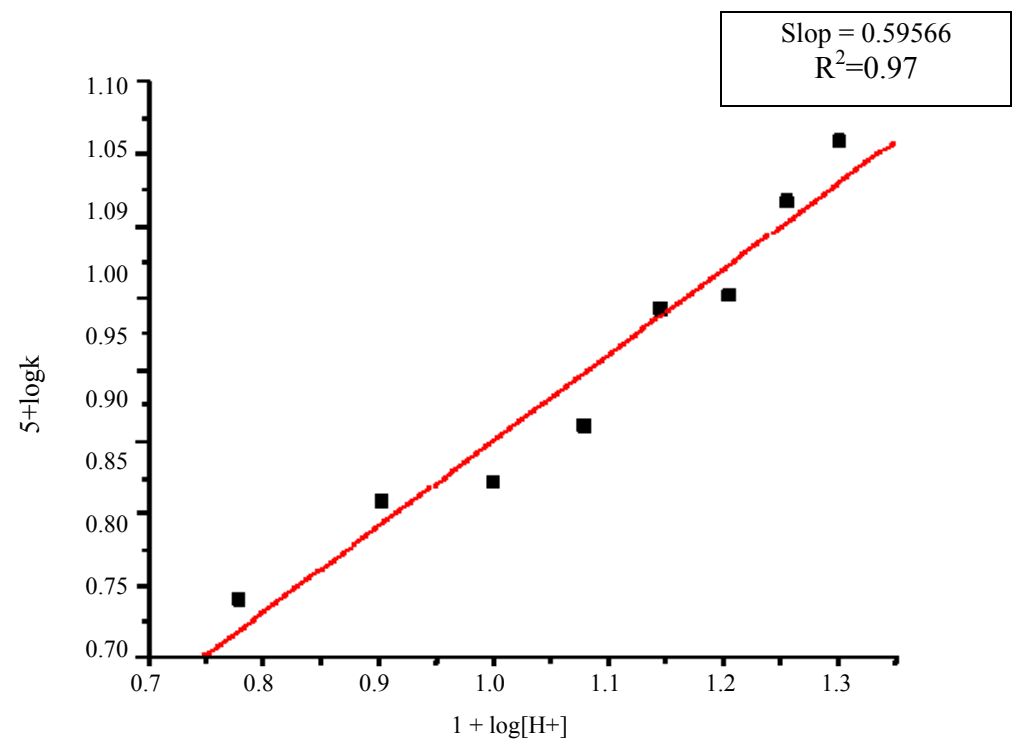

Figure 2. Effect of $\left[\mathrm{H}^{+}\right]$on rate of oxidation of EDTA with PFC $\left(\log \mathrm{k} \mathrm{v} / \mathrm{s} \log \left[\mathrm{H}^{+}\right]\right)$

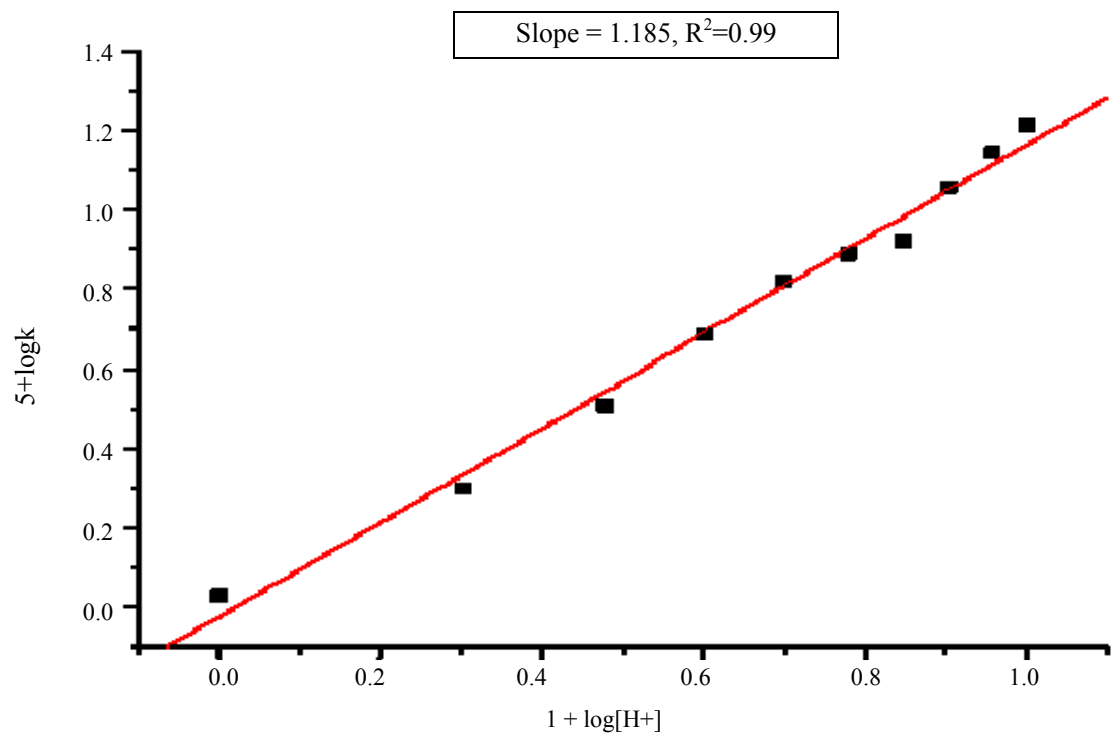

Figure 3. Effect of $\left[\mathrm{H}^{+}\right]$on rate of co-oxidation of IPA and EDTA with PFC (log k vs. $\log \left[\mathrm{H}^{+}\right]$)

\section{Zucker Hammett hypothesis}

This hypothesis is used to determine the role of water molecule in rate determining step. We plot a curve between log $\mathrm{k}$ vs. acidity function $\left(\mathrm{H}_{0}\right)$. If curve found to be linear with slop equal to one then we say that water molecule act as proton abstractor in rate determining step. We get a linear plot (Figure 4, Table 2) with slope $=0.92$ (equal to one) so this proves water molecule act as proton abstractor agent in rate determining step. 
Table 2. Variation of rate with acidity function $\left(\mathrm{H}_{0}\right)$ on co-oxidation of IPA+EDTA by PFC

\begin{tabular}{ccccc}
\multicolumn{5}{c}{$[\mathrm{IPA}]=0.01, \mathrm{M}[\mathrm{PFC}]=0.001$, solvent $=$ water, $[\mathrm{EDTA}]=0.1, \mathrm{M}$ temp $=30^{\circ} \mathrm{C}$} \\
\hline S.No. & Concentration of Perchloric acid & AcidityFunction $\left(\mathrm{H}_{0}\right)$ & $\mathrm{k} \mathrm{x} 10^{+5}$ & $4+\operatorname{logk}$ \\
\hline 1 & $0.2 \mathrm{M}$ & 1.78 & 14.04 & 0.1477 \\
2 & $0.4 \mathrm{M}$ & 1.44 & 19.99 & 0.3010 \\
3 & $0.6 \mathrm{M}$ & 1.25 & 27.80 & 0.4445 \\
4 & $0.8 \mathrm{M}$ & 1.12 & 36.70 & 0.5646 \\
5 & $1.0 \mathrm{M}$ & 1.01 & 46.40 & 0.6666 \\
6 & $1.5 \mathrm{M}$ & 0.83 & 101.50 & 0.8661 \\
7 & $2.0 \mathrm{M}$ & 0.64 & 150.71 & 1.1782 \\
\hline
\end{tabular}

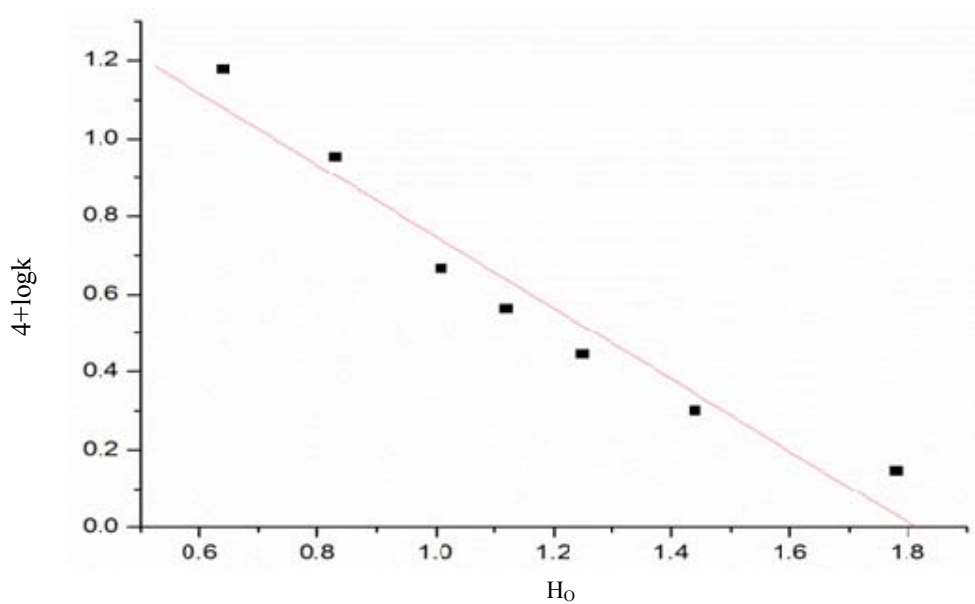

Figure 4. Variation of rate with acidity function $\left(\mathrm{H}_{0}\right)$ on co-oxidation of IPA+EDTA with PFC (Plot log k vs. acidity function $\mathrm{H}_{0}$ )

\section{Substrate variation}

Table 3 shows the effect of substrate variation on reaction rate. Rate of reaction increases with increase in concentration of substrate. Substrate concentration was varied from $0.008 \mathrm{M}$ to $0.04 \mathrm{M}$ and plot of $\log \mathrm{k} v \mathrm{ss}$. $\log$ [sub] was found to be linear. Order of reaction is found first order with respect to IPA (Figure 5) and EDTA (Figure 6). In mix set, we also studied effect of concentration variation on rate, reaction show half order $(0.58$ i.e.0.5) with respect to IPA (Figure 7) and fractional order is found 0.2 with respect to EDTA (Figure 8)

Table 3. Variation of rate with substrate concentration Temp $=30^{\circ} \mathrm{C}, \quad \mathrm{PFC}=1 \times 10^{-3} \mathrm{M}, \quad\left[\mathrm{H}^{+}\right]=1 \mathrm{M}, \quad$ Solvent $=$ water

\begin{tabular}{cccc}
\hline S. No. & $\begin{array}{c}\text { Concentration } \\
\text { of IPA, M }\end{array}$ & $\begin{array}{c}\text { Concentration of } \\
\text { EDTA, M }\end{array}$ & $\begin{array}{c}\mathrm{k} \text { value, } \\
\mathrm{k} \times 10^{5}\end{array}$ \\
\hline 1 & 0.008 & - & 10.59 \\
2 & 0.010 & - & 12.63 \\
3 & 0.014 & - & 16.90 \\
4 & 0.020 & - & 25.44 \\
5 & 0.025 & - & 28.71 \\
6 & 0.030 & - & 35.52 \\
7 & 0.040 & - & 54.50 \\
\hline
\end{tabular}




\begin{tabular}{cccc}
\hline 8 & 0.060 & - & 71.27 \\
9 & - & 0.008 & 10.09 \\
10 & - & 0.010 & 11.43 \\
11 & - & 0.014 & 14.39 \\
12 & - & 0.020 & 19.46 \\
13 & - & 0.025 & 22.79 \\
14 & - & 0.030 & 24.56 \\
15 & - & 0.040 & 32.66 \\
16 & - & 0.060 & 53.00 \\
17 & 0.008 & 0.010 & 48.51 \\
18 & 0.010 & 0.010 & 56.80 \\
19 & 0.014 & 0.010 & 73.00 \\
20 & 0.020 & 0.010 & 99.91 \\
21 & 0.025 & 0.010 & 106.62 \\
22 & 0.030 & 0.010 & 109.65 \\
23 & 0.040 & 0.010 & 118.52 \\
24 & 0.010 & 0.008 & 54.96 \\
25 & 0.010 & 0.014 & 64.79 \\
26 & 0.010 & 0.020 & 65.63 \\
27 & 0.010 & 0.025 & 70.54 \\
28 & 0.010 & 0.030 & 73.94 \\
29 & 0.010 & 0.040 & 78.76 \\
\hline
\end{tabular}

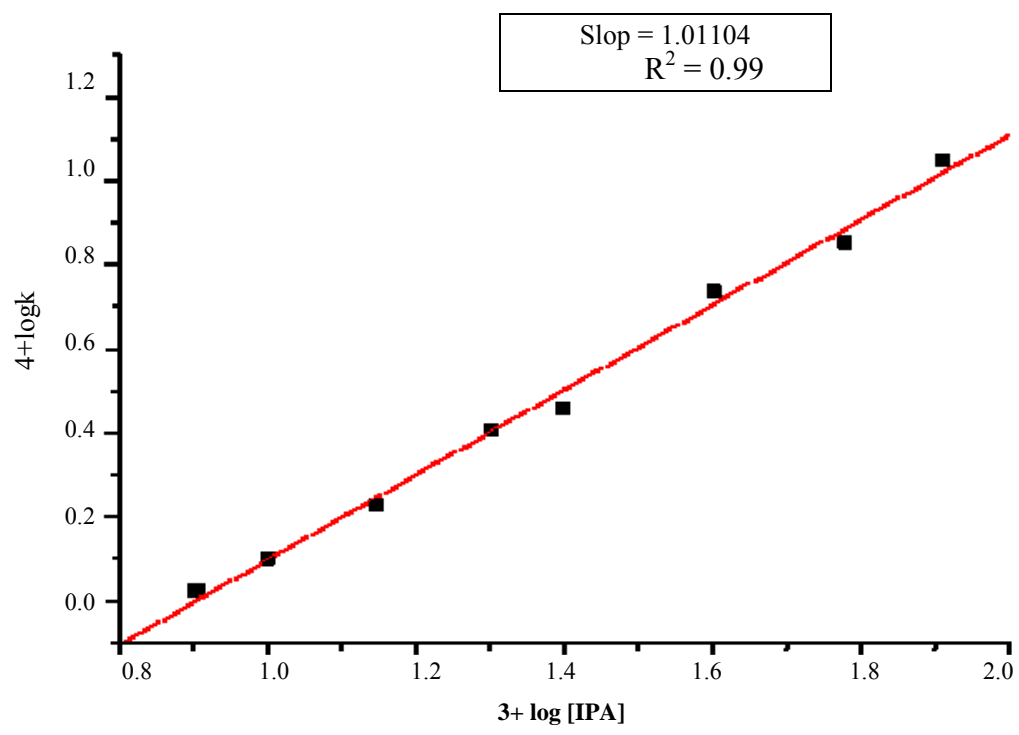

Figure 5. Effect of [IPA] on rate of oxidation of IPA with PFC (plot $\log \mathrm{k} v s . \log$ [IPA])

\section{Michaelis-Menten curve}

Figure 9 wide Table 4 shows the plot of 1/k versus 1/[EDTA] is linear with small positive intercept, indicates that Michaelis-Menten type kinetics is followed with respect to EDTA, so complex is formed between EDTA and PFC in rate determining step. 


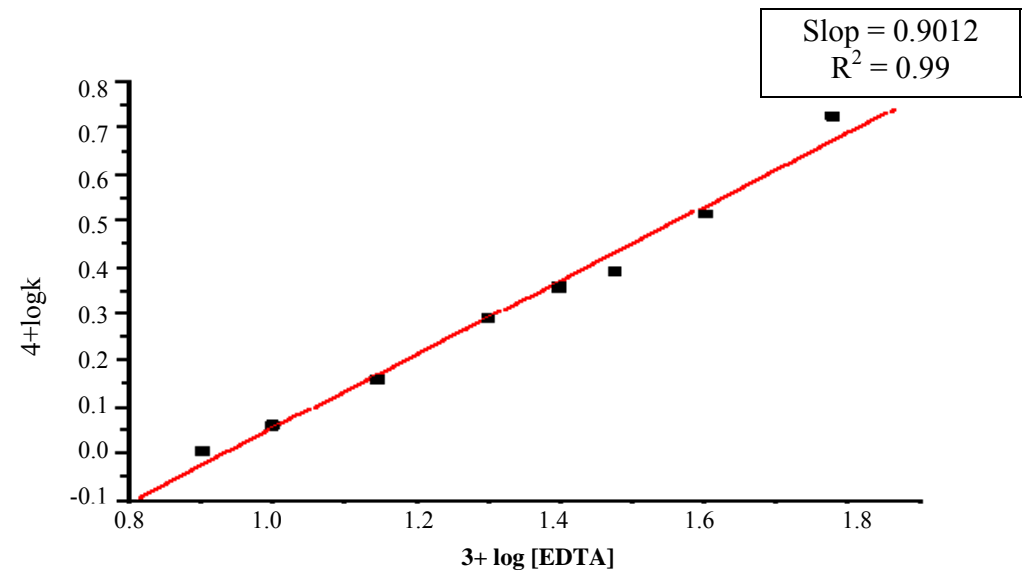

Figure 6. Effect of [EDTA] on rate of oxidation of EDTA with PFC (plot log k vs. $\log$ [EDTA])

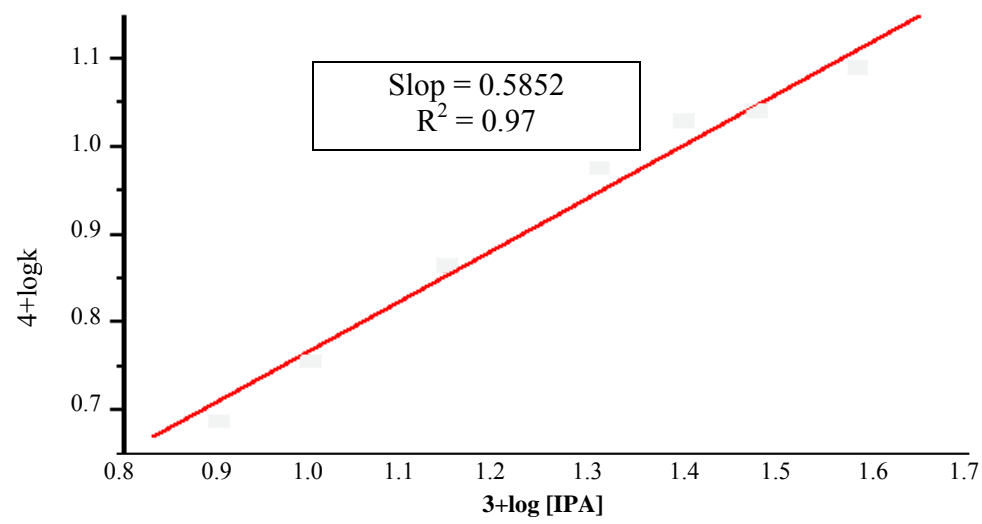

Figure 7. Effect of [IPA] on rate of co-oxidation of IPA+EDTA with PFC, (Plot log k vs. log [IPA])

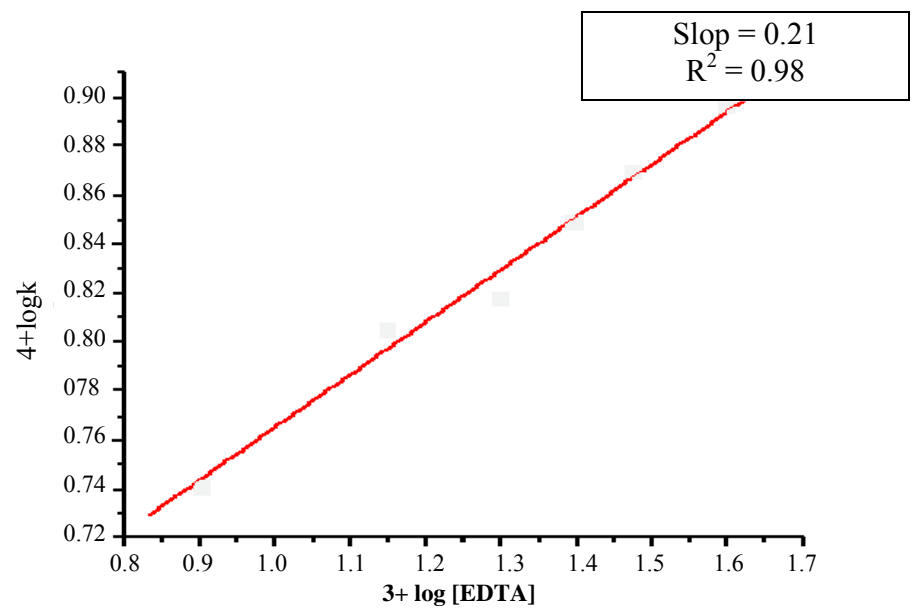

Figure 8. Effect of [EDTA] on rate of co-oxidation of IPA+EDTA with PFC, (plot log k vs. $\log$ [EDTA]) 
Table 4. Values of $1 /\left[\right.$ EDTA] and $1 / \mathrm{k}_{\mathrm{obs}}$ for Michaelis-Mentene plot

\begin{tabular}{ccc}
\hline S.No. & $1 /[$ EDTA] & $1 / \mathrm{k}($ Obs. $)$ \\
\hline 1 & 125.00 & 9906.87 \\
2 & 100.00 & 8748.90 \\
3 & 71.42 & 6947.82 \\
4 & 50.00 & 5138.74 \\
5 & 40.00 & 4387.88 \\
6 & 33.33 & 4071.66 \\
7 & 25.00 & 3061.84 \\
8 & 16.66 & 1886.79
\end{tabular}

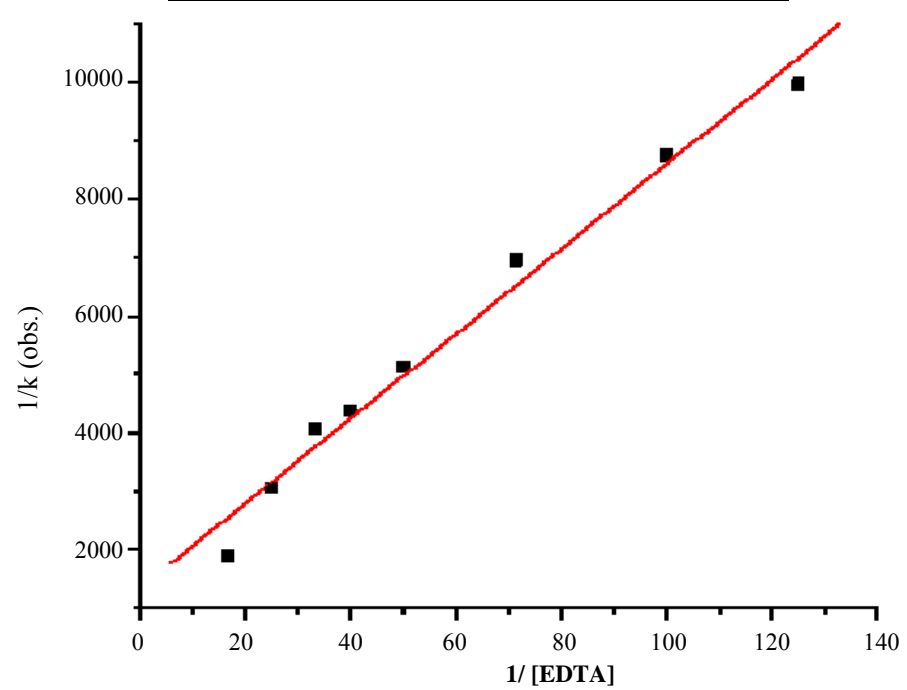

Figure 9. Michaelis-Menten plot

\section{Oxidant variation}

PFC used as an oxidant. It is taken in excess concentration, so there is no effect on rate constant on all substrate i.e. IPA, EDTA and IPA+EDTA (Table 5). The order with respect to PFC is one.

Table 5. Variation of rate with PFC concentrations

\begin{tabular}{|c|c|c|c|c|}
\hline Tem & $=30^{\circ} \mathrm{C}$ & Substrate $=1 \times 10$ & {$\left[\mathrm{H}^{+}\right]=1 \mathrm{M}$} & Solvent $=$ medium \\
\hline S.No. & Conc. of PFC, $\mathrm{M}$ & $\mathrm{k} \times 10^{5}$ (IPA) & $\mathrm{k} \times 10^{5}$ (EDTA) & $\mathrm{k} \times 10^{5}(\mathrm{IPA}+\mathrm{EDTA})$ \\
\hline 1 & 0.00025 & 11.89 & 9.749 & 43.44 \\
\hline 2 & 0.0004 & 11.90 & 10.77 & 44.58 \\
\hline 3 & 0.0005 & 12.01 & 10.55 & 43.56 \\
\hline 4 & 0.00075 & 10.02 & 11.16 & 43.22 \\
\hline 5 & 0.0009 & 11.65 & 9.17 & 42.33 \\
\hline 6 & 0.001 & 11.08 & 10.70 & 43.06 \\
\hline
\end{tabular}

\section{Effect of ionic strength}

Table 6 shows the effect of ionic strength. There is no effect in rate of reaction by changing sodium per chlorate concentration from $0.001-0.01 \mathrm{~mole}^{-3}$ on all substrate i.e. IPA, EDTA and IPA+EDTA. This shows absence ion- ion type interaction in rate determining step. 
Table 6. Variation of rate with sodium perchalorate concentration

\begin{tabular}{ccccc} 
Temp $=$ & $30^{\circ} \mathrm{C}$, Substrate $=1 \times 10^{-2} \mathrm{M}, \mathrm{PFC}=1 \times 10^{-3} \mathrm{M},\left[\mathrm{H}^{+}\right]=1 \mathrm{M}$, Solvent = medium \\
\hline S.No. & Conc. of $\mathrm{NaClO}_{4}$ & $\mathrm{k} \times 10^{5}$ (IPA) & $\mathrm{k} \times 10^{5}$ (EDTA) & $\mathrm{k} \times 10^{5}$ (IPA + EDTA) \\
\hline 1 & 0.0010 & 12.167 & 13.25 & 65.36 \\
2 & 0.0014 & 11.66 & 14.10 & 64.25 \\
3 & 0.0020 & 11.131 & 13.15 & 64.56 \\
4 & 0.0033 & 11.89 & 13.78 & 61.68 \\
5 & 0.0050 & 11.63 & 13.36 & 63.90 \\
6 & 0.0100 & 12.09 & 13.91 & 62.56 \\
\hline
\end{tabular}

\section{Solvent variation}

Table 7, 8 and 9 show that rate of reaction increases by decreasing dielectric constant in all the three substrate i.e. IPA, EDTA and IPA+EDTA. The plot of log $\mathrm{k}$ against 1/D (dielectric constant) is linear with positive slope indicating the presence of either dipole-dipole or iondipole type of interaction between the oxidant and substrate (Figures 10, $12 \& 14$ ). Plot of log $\mathrm{k}$ against (D-1/2D+1) is curvature indicating absence of dipole-dipole interaction in the rate determining step (Figures 11, 13 \& 15). Positive slope of log $\mathrm{k}$ against 1/D plot indicated that the reaction involves cation-dipole type of interaction in the rate determining step.

Table 7. Variation of rate with tetrahydrofuran concentration (For IPA)

\begin{tabular}{cccccc}
\multicolumn{2}{c}{ Temp $=30^{\circ} \mathrm{C}$} & \multicolumn{2}{c}{$\mathrm{IPA}=\mathrm{M} / 100$} & \multicolumn{3}{c}{$\mathrm{PFC}=\mathrm{M} / 1000$} & {$\left[\mathrm{H}^{+}\right]=1 \mathrm{M}$} \\
\hline S.No. & Water : THF $\%(\mathrm{~V} / \mathrm{V})$ & $\mathrm{D}_{\text {mix }}$ & $1 / \mathrm{D}$ & $\mathrm{D}-1 / 2 \mathrm{D}+1$ & $\mathrm{k} \mathrm{x} 10^{5}$ \\
\hline 1 & $100: 00$ & 80.00 & 0.0125 & 0.4906 & 13.22 \\
2 & $95: 05$ & 78.82 & 0.0126 & 0.4906 & 28.05 \\
3 & $90: 10$ & 77.55 & 0.01289 & 0.4803 & 39.95 \\
4 & $85: 15$ & 76.05 & 0.01314 & 0.4902 & 49.93 \\
5 & $80: 20$ & 74.4 & 0.01344 & 0.489 & 60.64 \\
6 & $75: 25$ & 72.44 & 0.0138 & 0.4897 & 73.50 \\
\hline
\end{tabular}

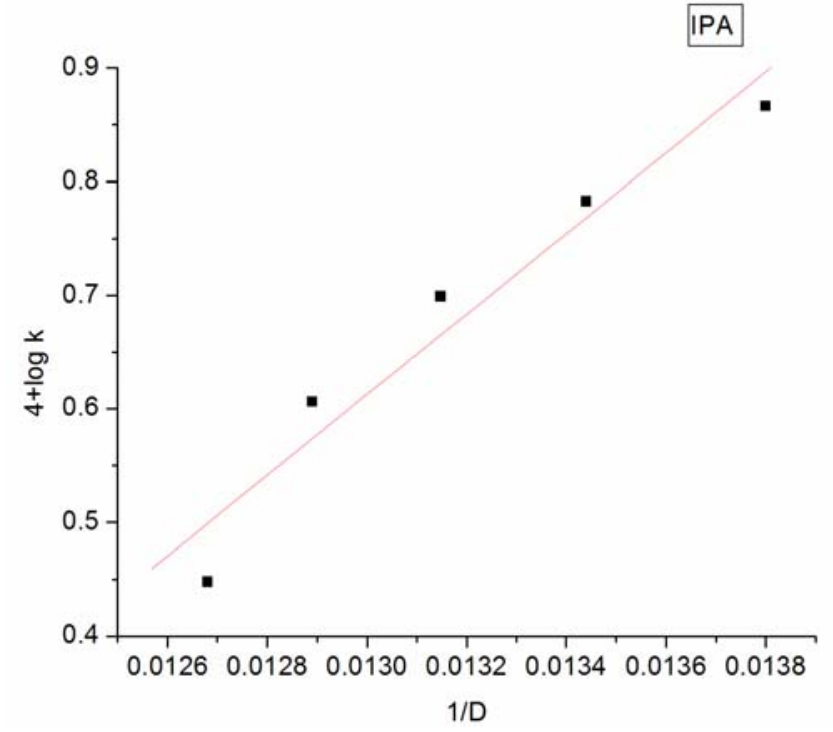

Figure 10. Plot between 1/D and $4+\log \mathrm{k}$ (For IPA) 


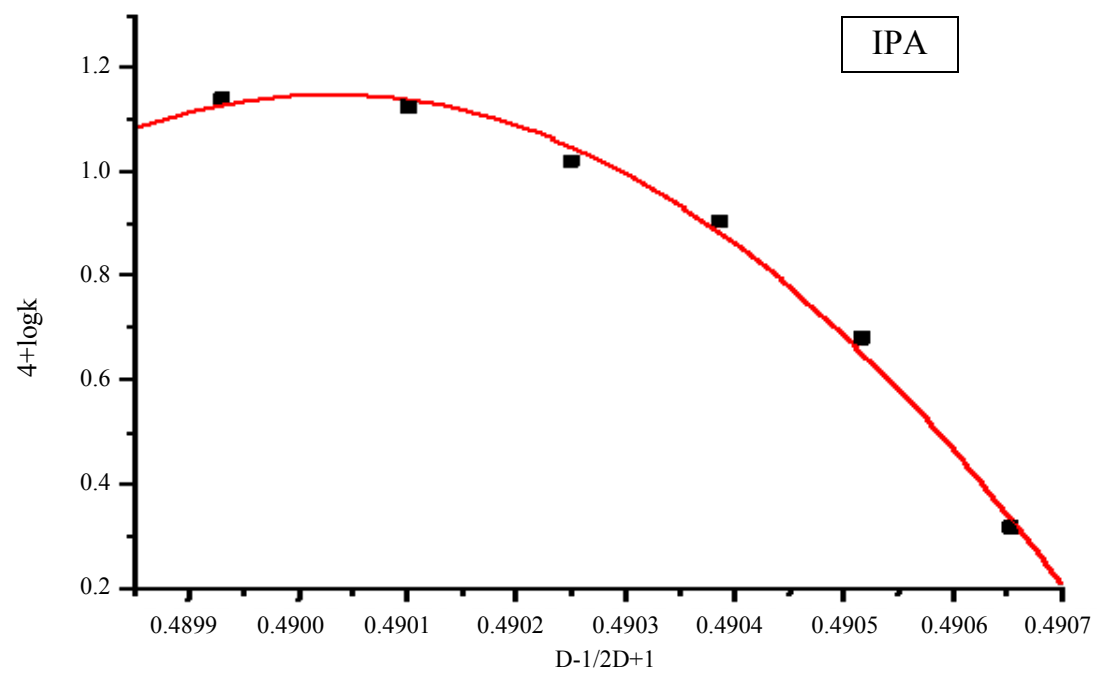

Figure 11. Plot between D-1/2D+1 and $4+\log k$ (For IPA)

Table 8. Variation of rate with tetrahydrofuran concentration (For EDTA) Temp $=30^{\circ} \mathrm{C} \quad \mathrm{EDTA}=\mathrm{M} / 100 \quad \mathrm{PFC}=\mathrm{M} / 1000 \quad\left[\mathrm{H}^{+}\right]=1 \mathrm{M}$

\begin{tabular}{cccccc}
\hline S.No. & Water : THF \% (V/V) & $\mathrm{D}_{\operatorname{mix}}$ & $1 / \mathrm{D}$ & $\mathrm{D}-1 / 2 \mathrm{D}+1$ & $\mathrm{k} \times 10-5$ \\
\hline 1 & $100: 00$ & 80.00 & 0.0125 & 0.4906 & 14.43 \\
2 & $95: 05$ & 78.82 & 0.01260 & 0.4906 & 44.33 \\
3 & $90: 10$ & 77.55 & 0.01289 & 0.4803 & 51.04 \\
4 & $85: 15$ & 76.05 & 0.01314 & 0.4902 & 57.88 \\
5 & $80: 20$ & 74.40 & 0.01344 & 0.4890 & 62.18 \\
6 & $75: 25$ & 72.44 & 0.01380 & 0.4897 & 67.82 \\
\hline
\end{tabular}

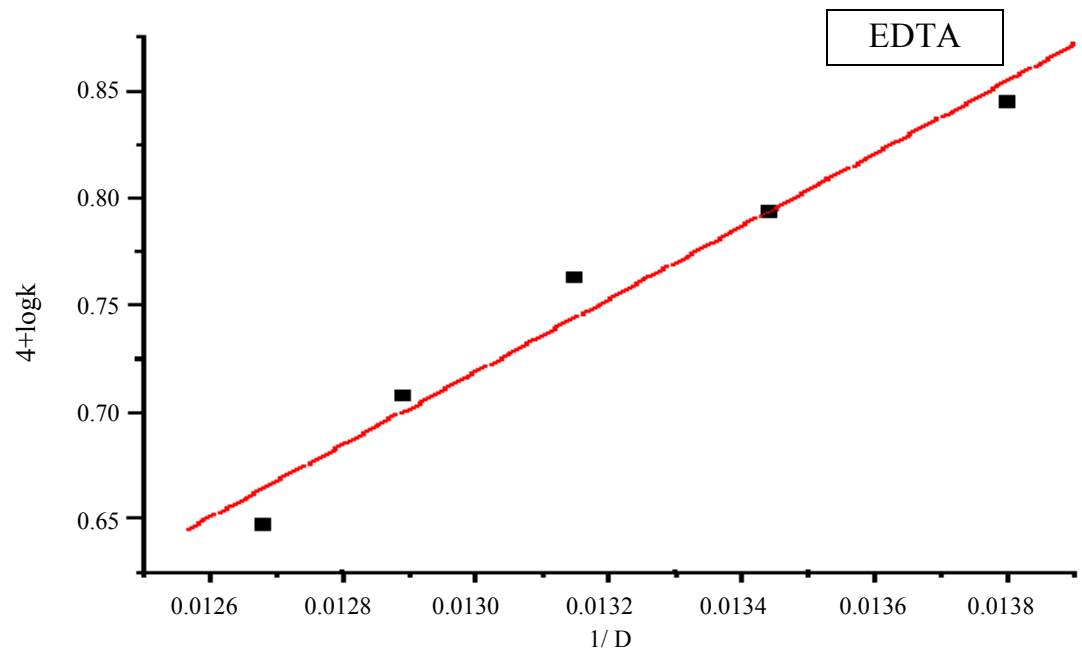

Figure 12. Plot between $1 / \mathrm{D}$ and $4+\log \mathrm{k}$ (For EDTA) 


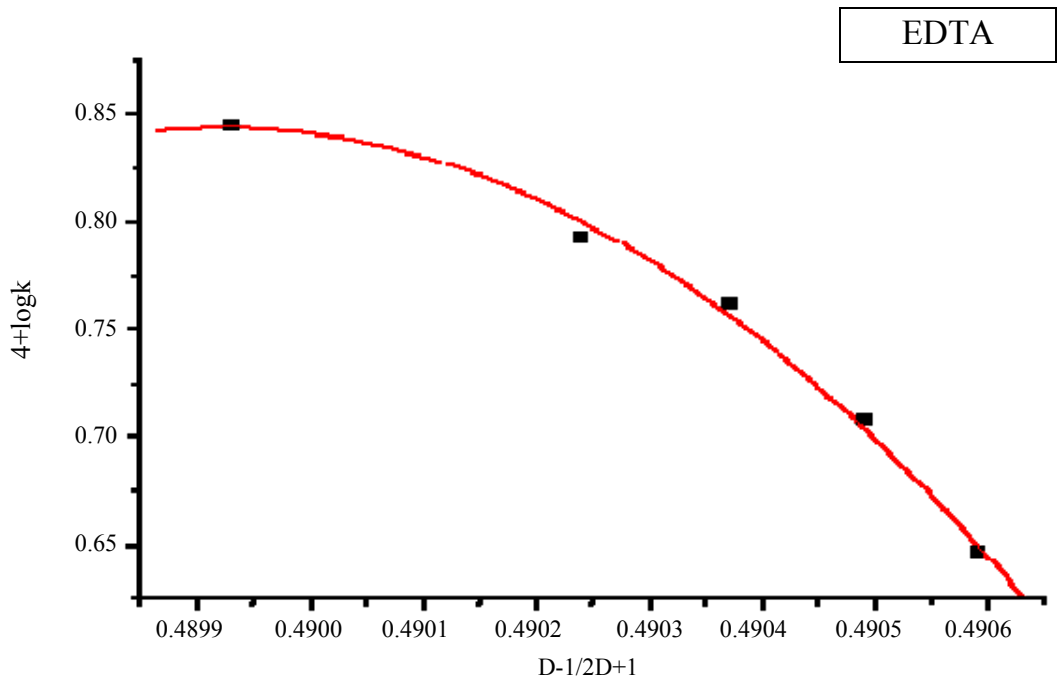

Figure 13. Plot between D-1/2D +1 and $4+\log k$ (For EDTA)

Table 9. Variation of rate with tetrahydrofuran concentration (For IPA+EDTA)

\begin{tabular}{|c|c|c|c|c|c|}
\hline Temp $=3$ & IPA $=M / 100$ & EDTA & $\mathrm{M} / 100$ & $\mathrm{PFC}=\mathrm{M} / 1000$ & {$\left[\mathrm{H}^{+}\right]=1 \mathrm{M}$} \\
\hline S.No. & Water : THF \% (V/V) & $\mathrm{D}_{\text {mix }}$ & $1 / \mathrm{D}$ & $\mathrm{D}-1 / 2 \mathrm{D}+1$ & $\mathrm{k} \times 10-5$ \\
\hline 1 & $100: 00$ & 80.00 & 0.0125 & 0.4906 & 56.80 \\
\hline 2 & $95: 05$ & 78.82 & 0.01260 & 0.4906 & 83.63 \\
\hline 3 & $90: 10$ & 77.55 & 0.01289 & 0.4803 & 113.53 \\
\hline 4 & $85: 15$ & 76.05 & 0.01314 & 0.4902 & 120.79 \\
\hline 5 & $80: 20$ & 74.40 & 0.01344 & 0.4890 & 124.82 \\
\hline 6 & $75: 25$ & 72.44 & 0.01380 & 0.4897 & 138.14 \\
\hline
\end{tabular}

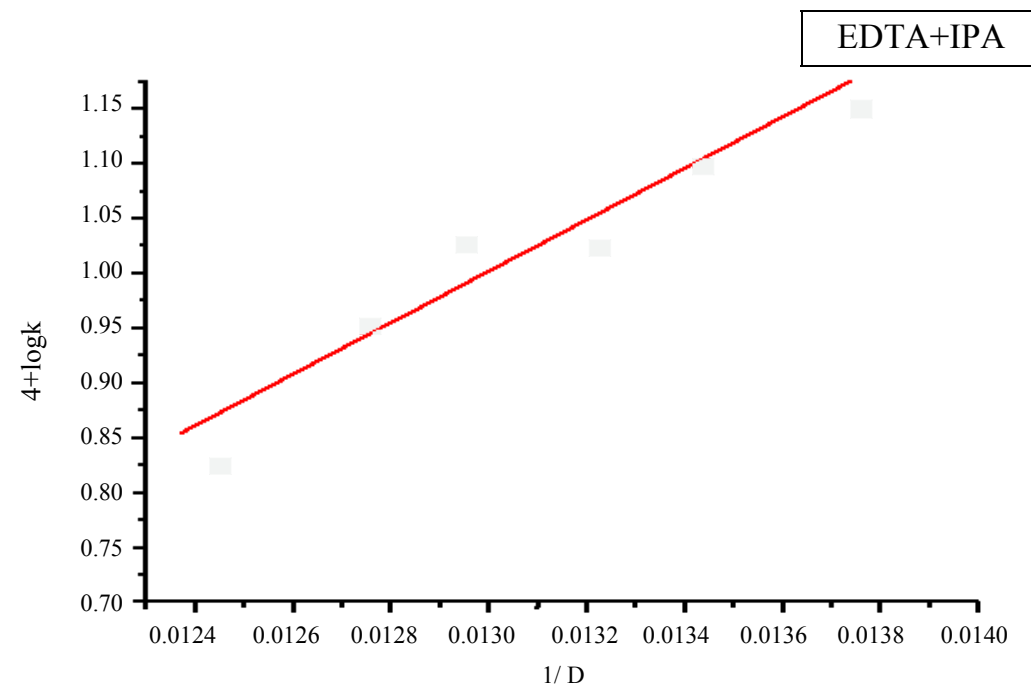

Figure 14. Plot between $1 / \mathrm{D}$ and $4+\log \mathrm{k}($ For EDTA + IPA) 


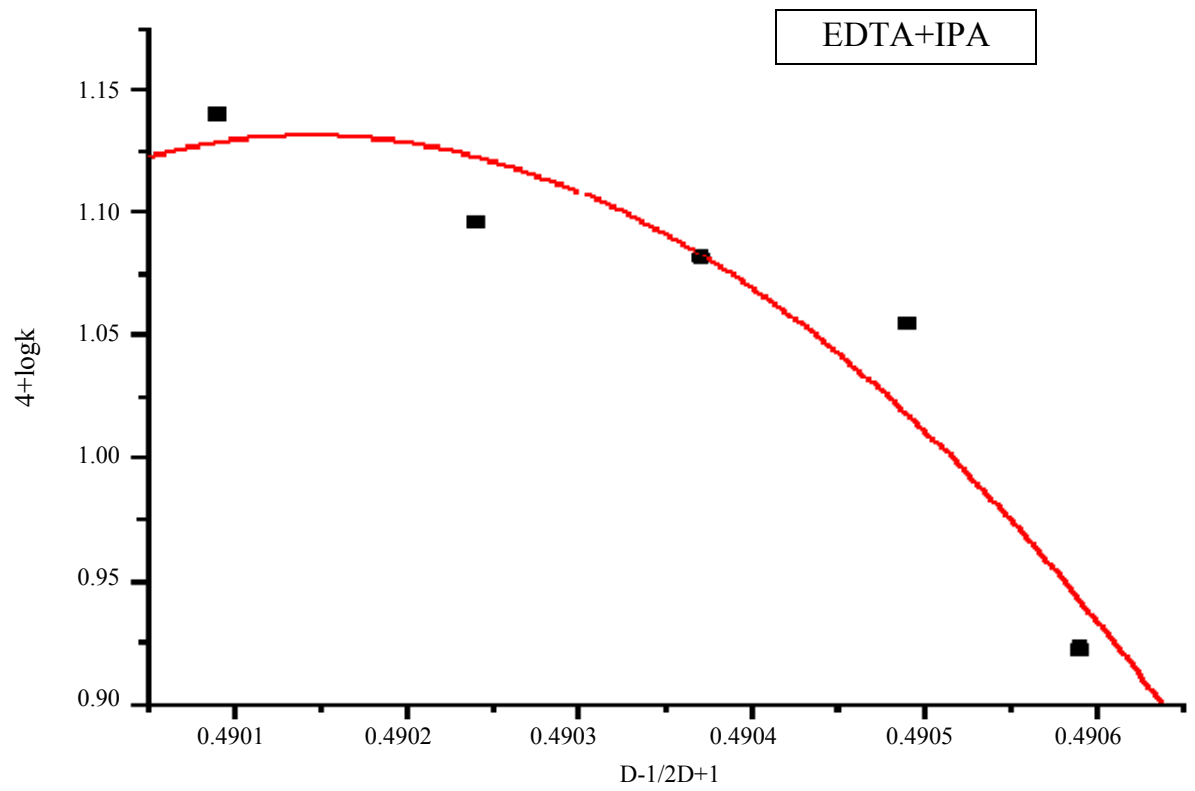

Figure 15. Plot between D-1/2D +1 and $4+\log \mathrm{k}($ For EDTA + IPA)

\section{Free radical test}

The reaction mixture in kinetic conditions to which a known amount of acrylonitrile scavenger has been added initially was kept for 24 hours in an inert atmosphere of $\mathrm{N}_{2}$ fail to induce the polymerization of acrylonitrile. Then on dilution of the reaction mixture with methanol no turbidity occurred, indicating that one-electron oxidation was unlikely.

\section{Activation energy}

The rate of oxidation of IPA, EDTA and mixture of both compounds (IPA + EDTA) were determined at different temperature and the reaction obeys Arrhenius equation. Results are summarized in Table 10. Energy of activation was calculated by slope of straight line obtained plotting $\log \mathrm{k}$ versus $1 / \mathrm{T}$ (Figure 16). The energy of activation is found $67.55 \mathrm{kcal}^{-\mathrm{mol}^{-1}}$ for IPA \& $69.71 \mathrm{kcal}$. mol ${ }^{-1}$ for EDTA and $42.52 \mathrm{kcal} \mathrm{mol}^{-1}$, (IPA + EDTA). That is prove that rate of reaction increase when both compounds take together, means one of them is act as a catalyzed.

Table 10. Variation of rate with temperature

\begin{tabular}{|c|c|c|c|c|c|}
\hline & \multicolumn{2}{|c|}{ Substrate $=M / 100$} & \multicolumn{2}{|c|}{$\mathrm{PFC}=\mathrm{M} / 1000$} & {$\left[\mathrm{H}^{+}\right]=1 \mathrm{M}$} \\
\hline S.No. & $\begin{array}{c}\text { Temp. } \\
{ }^{\circ} \mathrm{K}\end{array}$ & $1 / \mathrm{T} \times 10^{-3}$ & $\mathrm{k} \times 10^{5}$ (IPA) & $\begin{array}{c}\mathrm{k} \times 10^{5} \\
(\mathrm{EDTA})\end{array}$ & $\begin{array}{c}\mathrm{k} \times 10^{5} \\
(\mathrm{IPA}+\mathrm{EDTA})\end{array}$ \\
\hline 1 & 298 & 3.355 & ------ & ------ & 37.96 \\
\hline 2 & 303 & 3.300 & 12.63 & 9.10 & 56.80 \\
\hline 3 & 308 & 3.246 & 18.36 & 16.77 & 80.60 \\
\hline 4 & 313 & 3.194 & 22.92 & 25.56 & 108.73 \\
\hline 5 & 318 & 3.144 & 38.34 & 36.81 & 123.82 \\
\hline 6 & 323 & 3.096 & 54.42 & 57.88 & ------ \\
\hline
\end{tabular}




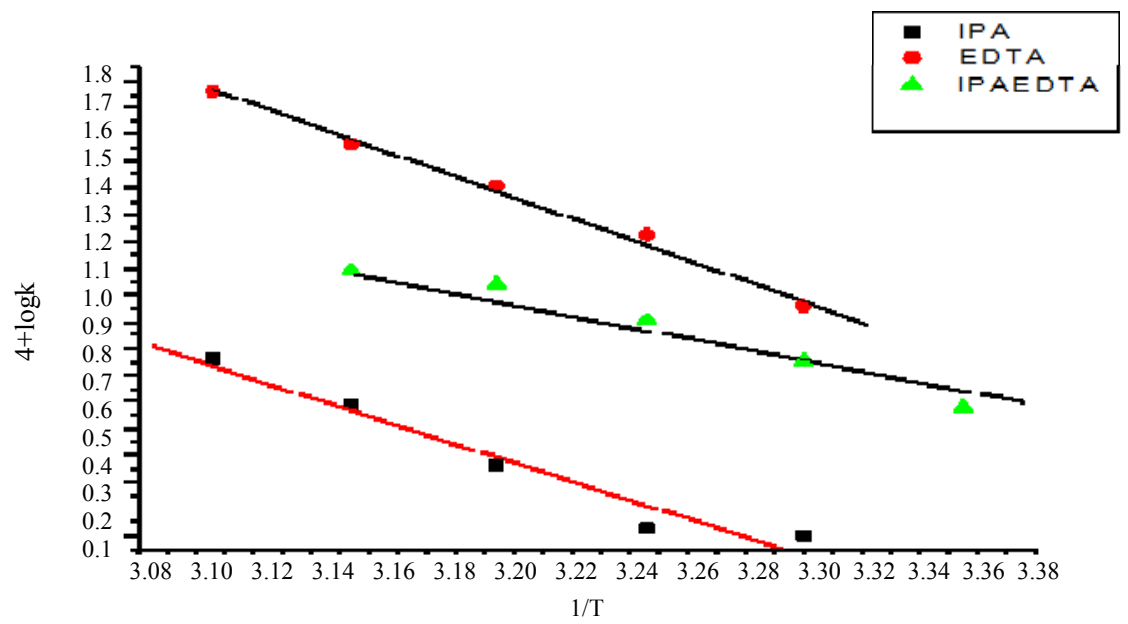

Figure 16. Plot between $1 / \mathrm{T}$ and $4+\log \mathrm{k}$

Thermodynamics parameters

With the help of activation energy, various thermodynamic Parameters like entropy of activation and free energy of activation evaluated as given in Table 11.

Table 11. Thermodynamic parameters

\begin{tabular}{lccc}
\hline Substrate & $\begin{array}{c}\text { Energy of activation } \\
\mathrm{kcal} . \mathrm{mol}^{-1}\end{array}$ & $\begin{array}{c}\Delta \mathrm{S}^{\#} \\
\mathrm{JK}^{-1} \mathrm{~mol}^{-1}\end{array}$ & $\begin{array}{c}\Delta \mathrm{G}^{\#} \\
\mathrm{kJmol}^{-1}\end{array}$ \\
\hline IPA & 67.55 & -309.75 & 91.26 \\
EDTA & 69.71 & -309.33 & 91.13 \\
EDTA+IPA & 42.52 & -323.99 & 95.69 \\
\hline
\end{tabular}

Mechanism

On the basis of above experimental results following mechanism has been given

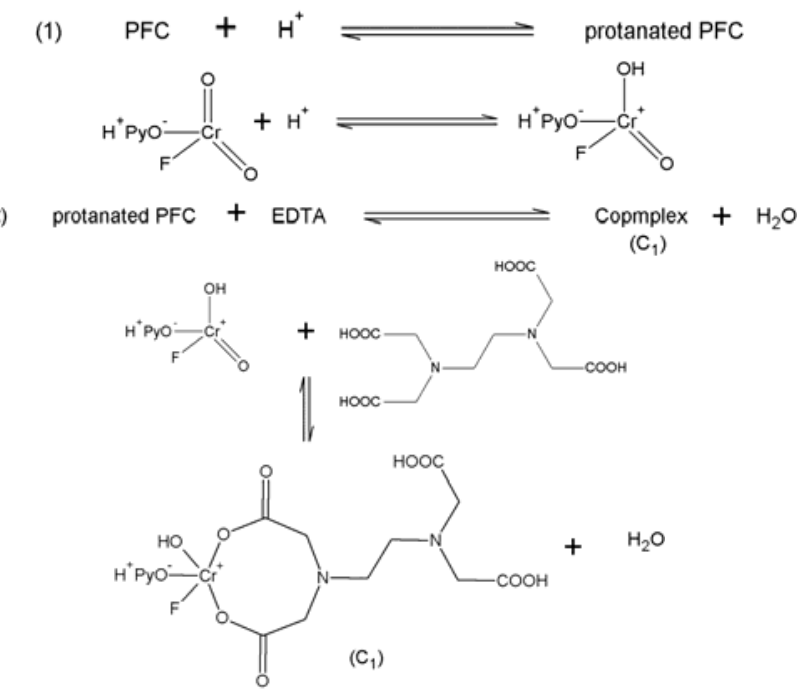



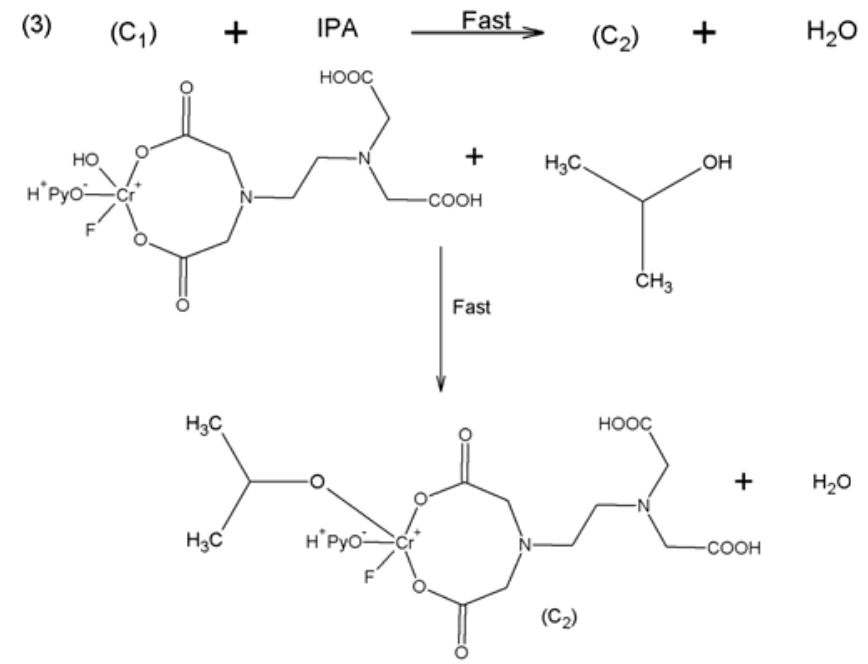

(4) $\left(\mathrm{C}_{2}\right) \underset{\mathrm{RDS}}{\stackrel{\mathrm{H}_{2} \mathrm{O}}{\longrightarrow}}$ Aceton $+\mathrm{Cr}(\mathrm{IV})$ species + Hydronium ion

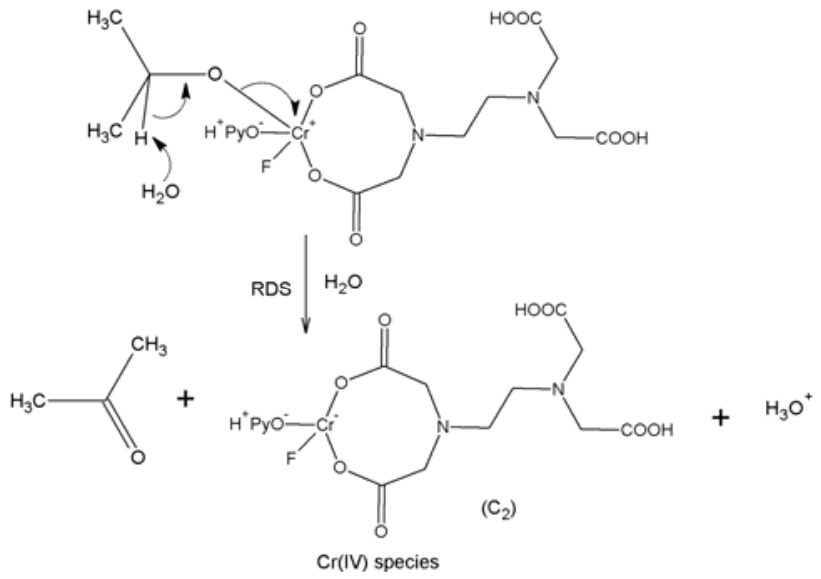

(5) $\mathrm{Cr}(\mathrm{IV})+\mathrm{Cr}(\mathrm{VI}) \longrightarrow 2 \mathrm{Cr}(\mathrm{V})$

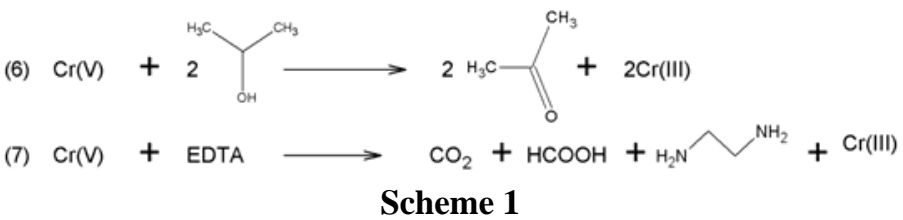

\section{References}

1. Hiran B L, Meena, M 1 and Khuntwal J, Der Pharma Chemica, 2010, 2(5), 470-478.

2. Jain S, Hiran B L and Bhatt C V, J Chem., 2009, 6(1), 237-246; DOI:10.1155/2009/907071

3. Ahmed S, Shafi Z, Mansoor S S and Sheik S, Asian J Res Chem., 2012, 5(6), 753-758.

4. Aparna P, Kothari S and Banerji K K, Proc Indian Acad Sci., 1995, 107(3), 213-220.

5. Ozgun B, Commun Fac Sci Uni Ank Series B, 1996, 42, 33-38. 
6. Pandeeswarab M, John B, Bhuvaneshwari D S and Elango K P, J Serb Chem Soc., 2005, 70(2), 145-151.

7. Sharma S, Ramani J, Bhalodia J and Thakkar F, Der Chemica Sinica, 2011, 2(4), 140- 151 .

8. Gurumurthy R, Gopalkrishnan M, Kartiketyan B and Selvaraju M, Asian J Chem., 1998, 10(3), 476-479.

9. Fatimajenthi G, Kumar V G and Elango K P, J Serb Chem Soc., 2002, 67(12), 803-808.

10. Abraham G, Kumar R, Arabindoo B and Murugeson V, Indian J Chem., 2000, 39(B), 74-75.

11. Khurana M, Sharma P K and Banerji K K, Proc Indian Acad Sci (Chem Sci.), 2000, 112(2), 73-81.

12. Dave I, Sharma V and Banerji K K, Indian J Chem., 2002, 41(A), 493-499.

13. Prakash O, Sindal R S and Sharma P K, Int J Chem Sci., 2003, 1(4), 411-420.

14. Dhariwal V, Yajurvedi D and Sharma P K, Indian J Chem., 2006, 45(A), 1158-1164.

15. Santhosh V K and Rukmangathan M, Asian J Chem., 2010, 22(10), 7535-7540.

16. Shivamurti A, Sangappa C, Sharanappa B K and Nandibewoor T, Trans Met Chem., 2002, 27(7), 704-711; DOI:10.1023/A:1020395920573

17. Hesham A A Medien, Z. Naturforsch. 2003, 58(b), 1201-1205.

18. Khan Z, Masan S and Kabir-ud-din, Trans Met Chem., 2003, 28(8), 881-887; DOI:10.1023/A:1026303415289

19. Khan Z and Kabir-Ud-Din, Transition Met Chem., 2002, 27(8), 832-839; DOI:10.1023/A:1021382505230

20. Shan J H, Fan 1, Huo Y S, Han C and Shen G S. Inorganic Reaction Mechanism, 2008, 6(4), 281-286; DOI:10.1515/IRM.2008.6.4.281

21. Bayen, Das R and Asim K, Open Catalysis Journal, 2009, 2, 71-78.

22. Kabir-ud-din, Morshed A, Azmal M, and Khan Z, Int J Chem Kinet., 2003, 35(11), 543-554; DOI:10.1002/kin.10146

23. Rajalakshmi k, Ramachandramoorthy T and Srinivasan S, Chemica Sinica, 2012, 3(2), 336-342.

24. Kabir-Ud-Din, Khaled H and Khan Z, Trans Met Chem., 2002, 27(6), 617-624; DOI:10.1023/A:1019819316240

25. Corey E J and Suggs W J, Tetrahedron Lett., 1975, 16(31), 2647-2650; DOI:10.1016/S0040-4039(00)75204-X

26. Khan Z, Raju and Kabir-Ud-Din, Indian J Chem., 2004, 43(B), 149-156.

27. Felgl F, Organic, Analysis, Elsevier, Amsterdam, 1956, 40, 396. 